\title{
THE EVALUATION OF FOREST FUNCTIONS OF FLOOD CONTROL AND WATER RESOURCES CONSERVATION
}

\author{
KOJI TAMAI \\ Forestry \& Forest products Research Institute, Japan
}

\begin{abstract}
Forests have the functions of 'flood control' and 'water resources conservation'. The forest management system for suitable water runoff will change according to the relationship between two functions whether trade-off or compatible. Therefore, the relationship between the two functions is examined in this report. The simulated water runoff from watersheds those were once bare hill and were covered by forests with 0 to 100 years old were analysed. The process-based model that reproduces each simple process of water movement in the forested basin was used to simulate the water runoff under the conditions of different forest soils and vegetation. As results, the developed forest soil has the effect to reduce runoff during high water and increase runoff during drought. This effect is called 'runoff delay effect'. On the other, developed forest vegetation has the effect to reduce runoff during low and drought due to evapotranspiration, but has little effect on runoff during high water. These results mean that the both forest functions of 'flood control' and 'water resources conservation' derives from the work of the developed forest soil. Then two functions are concluded to be compatible. From the above results, forest management system for suitable water runoff should have the first purpose of forest soil conservation. Forest vegetation plays an important role in conserving forest soils. Poor forest vegetation results in surface erosion and land slide resulting in loss of forest soil. Even when harvesting forest vegetation, the works should be taken to preserve the forest soil. In areas where water resources are scarce, suboptimal measures may be used to reduce forest vegetation to reduce evapotranspiration. It may be necessary to determine the amount of forest vegetation by comparing the risk of soil loss and the expected increase in drought runoff.
\end{abstract}

Keywords: forest soil, forest vegetation, flow duration curve.

\section{INTRODUCTION}

Forests are expected to have a Flood control function for reducing runoff volume at flooding and a Water resources conservation function for increasing runoff volume during times of drought. However, how these two functions develop their respective capabilities has not been identified. The two functions of flood control and water resources conservation might share a trade-off relation; alternatively, they are developed by the same mechanism. A policy of forest management to maintain the suitable water runoff characteristics for human beings depends on the relations linking the two functions. This report identifies relations between flood control function and water resources conservation function of a forest with reviewing the previous studies. Policies furthering forest management to develop these two functions are determined.

\section{DEFINITION OF EVALUATION INDICATORS}

\subsection{Effects of forest soil and vegetation}

A part of precipitation on the forest adheres to leaves and the bark of trees. Then it evaporates to the atmosphere without reaching the forest floor. It is called Canopy interception. Other parts of the precipitation reach the ground. Then it reaches streams with two forms, 

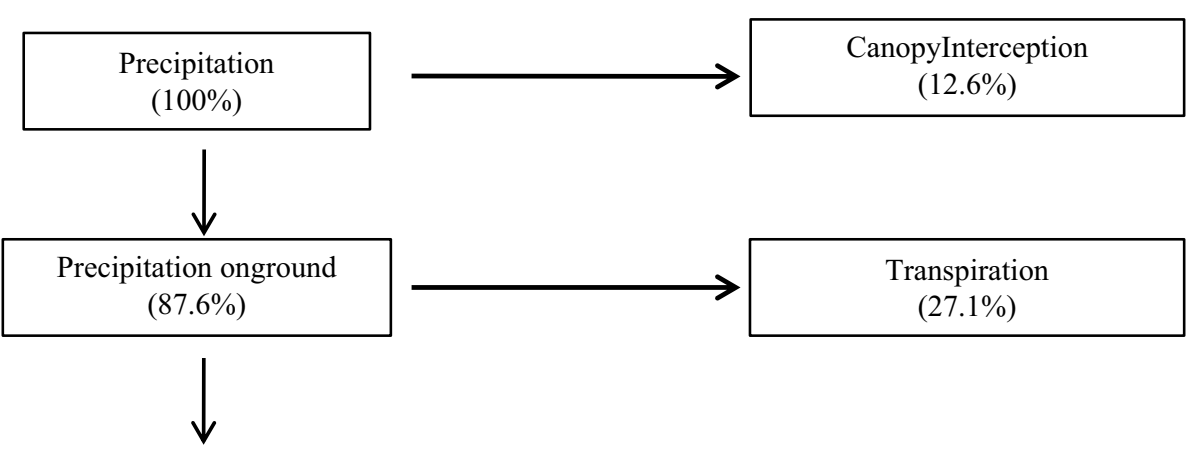

Direct runoff $(13.2 \%)$

Base flow $(39.0 \%)$

Figure 1: Simple processes of water movement in forested catchment and breakdown of water distribution in each process (Source: Abe, et al., 1997).

mainly. Direct runoff water infiltrates into shallower parts of the soil and flows out promptly to streams. Base flow water infiltrates deeply into the soil and flows out slowly to streams. Transpiration water is once absorbed by trees and then returned to the atmosphere. Precipitation water coming down to the forest passes out from the forest through various processes to the atmosphere and streams, at last. Breakdowns of water amounts distributed in each process differ according to forest conditions. Figure 1 presents an example of a secondary forest of deciduous broad-leaved trees at Yamashiro experimental catchment $\left(34.79^{\circ} \mathrm{N}\right.$, $\left.135.85^{\circ} \mathrm{E}\right)$.

The distribution ratio to direct runoff and base flow depends on the infiltration capacity of forest soil. With a forest having higher infiltration capacity, direct runoff and base flow are expected to be lower and larger, respectively. Such forest soil action with higher infiltration capacity is designated as runoff delay effect that is regarded as improving both functions for flood control and water resources conservation, whereas water level at flooding and drought is expected to reduce and increase, respectively.

Canopy interception and transpiration, the main routes to the atmosphere, are actions by forest vegetation. They are expected to reduce the water amount in the forest soil and also reduce the runoff volume in any time. Such actions by forest vegetation are designated as Evapotranspiration effect, which is said to reduce runoff volume at flooding and to have negative effects against water resources conservation function because of reduced runoff volume during times of drought

\subsection{Flow duration curve}

Flow volume increases rapidly in the aftermath of rainfall events and decrease gradually after completion of such events. Flow volume increases again at the next rainfall event (Fig. 2). An irregular saw tooth-like curve is obtained if the daily runoff volume (365 or 366 in 1 year) is arranged chronologically. A curve in which 365 or 366 daily runoff volume data are arranged in descending order is designated as a flow duration curve (Fig. 3). The smaller the left portion of the flow duration curve is, the stronger is the flood control function. For larger right portions, the water resources conservation function is stronger. Therefore, flood control 


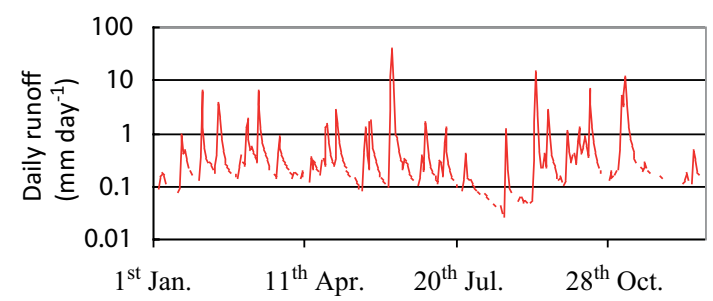

Figure 2: A fluctuation when daily runoff for 1 year is shown in chronological order.

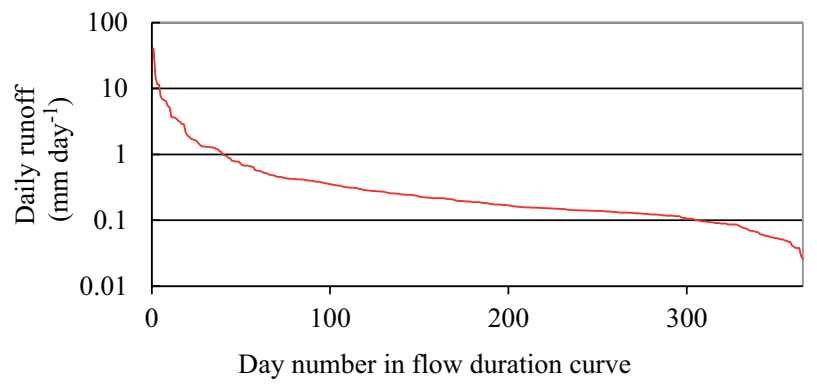

Figure 3: Flow duration curve in which daily runoff for 1 year sorted in descending order.

function and water resources conservation function are evaluated in this study by the values at the left end and right end of the flow duration curve, respectively.

\section{EVALUATION AND VERIFICATION}

\subsection{Evaluation by Hy-Cy model}

\subsubsection{Outline of Hy-Cy model}

The Hy-Cy model developed by Fukushima and Suzuki [1] is the process-based model to reproduce water movement in each process in the forested catchment as shown in Fig. 1. Calculated values of runoff by Hy-Cy model are used for evaluation of two functions. Many parameters are used in this model, such as parameter $\mathrm{D}_{50}$, which shows the degree of development of forest soil, which represents the effective thickness of the soil layer of the catchment. The larger this figure is, the more developed the forest soil gets. Many runoff volume observations are conducted in Tanakami Mountains $\left(35.0^{\circ} \mathrm{N}, 136.0^{\circ} \mathrm{E}\right)$ that used to be a bare hill made principally of granite. Trees are planted gradually in these areas in later 19th to earlier 20th centuries, but the areas are covered by forest at present. Fukushima [2] optimized parameters of Hy-Cy model using runoff data obtained from five catchments with different years after greenery work in Tanakami Mountains: Kiryu catchment (82 years after greenery work), Jakujo catchment (49 years after greenery work); Kawamukai B catchment (30 years after greenery work); Kawamukai A catchment (18 years after greenery work) and Rachi (bare) catchment ( 0 years after greenery work). The results show that parameters $\mathrm{D}_{50}$ increased with the lapse of time following greenery work (Fig. 4). It is then understood that the Hy-Cy model can simulate development of the forest soil appropriately by optimization of Hy-Cy model parameters using runoff observation data. 


\subsubsection{Evaluation method}

Parameters used in Hy-Cy model are broadly classifiable into soil-related part and vegetation-related part. Tani et al. [3] defined parameters in soil-related part and vegetation-related part for Kiryu catchment $\left(34.97^{\circ} \mathrm{N}, 135.99^{\circ} \mathrm{E}\right)$ as parameter set representing the conditions with forest soil and with forest vegetation, respectively. Similarly, parameters in soil-related part and vegetation-related part determined for Rachi (bare) catchment $\left(34.93^{\circ} \mathrm{N}, 135.97^{\circ} \mathrm{E}\right)$ are defined as parameter set representing the conditions without forest soil and without forest vegetation, respectively. Then, model calculation is performed while combinations of the soil-related part and vegetation-related part are changed to evaluate respective effects of forest soil and forest vegetation.

For the first calculation, both of soil-related and vegetation-related parameters obtained from the Kiryu catchment are used. For the second calculation, the soil-related and vegetation-related parameters obtained from Rachi (bare) catchment and Kiryu catchment, respectively, are used. For the third calculation, both of soil-related and vegetation-related parameters obtained from the Rachi (bare) catchment are used (Table 1). Effects by forest soil are evaluated with the comparison of calculation results between the first and the second calculations. Effects by forest vegetation are evaluated with the comparison of calculation results between the second and the third calculation (Table 1). The same precipitation data are used for all calculations.

\subsubsection{Results of evaluation}

Tani et al. [3] showed a flow duration curve from hourly runoff volume for 1 year obtained by calculations, The annual maximum hour runoff volume (left end of flow duration curve) and annual minimum hour runoff volume (right end of flow duration curve) are shown in Table 1.

Effects with/without forest soil can be evaluated by comparison between first and second calculation results. The annual maximum hourly runoff volume is about $9.3 \mathrm{~mm} \mathrm{~h}^{-1}$ (second calculation of without forest soil), and about $5.0 \mathrm{~mm} \mathrm{~h}^{-1}$ (first calculation with forest soil). The volume by the first calculation is apparently lower. The annual minimum hour runoff volumes are $0.002 \mathrm{~mm} \mathrm{~h}^{-1}$ and $0.01 \mathrm{~mm} \mathrm{~h}^{-1}$ by the first and second calculations, respectively. The volume by the first calculation is much larger. This result suggests that forest soil acts with

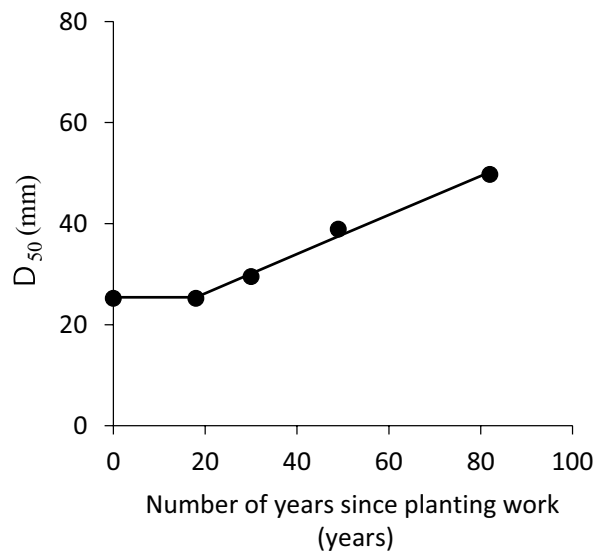

Figure 4: Relationship between the lapse of time following greenery work and the parameter $\mathrm{D}_{50}$ indicating the degree of forest soil development (Source: Fukushima, 1987). 
Table 1: Calculation result by Hy-Cy model (Source: Tani et al., 2012).

\begin{tabular}{lllll}
\hline Calculation & $\begin{array}{l}\text { Parameters for forest } \\
\text { soil }\end{array}$ & $\begin{array}{l}\text { Parameters for forest } \\
\text { vegetation }\end{array}$ & \multicolumn{2}{l}{ Hourly runoff (mm/hour) } \\
\cline { 4 - 5 } & & $\begin{array}{l}\text { Annual } \\
\text { maximum }\end{array}$ & $\begin{array}{l}\text { Annual } \\
\text { minimum }\end{array}$ \\
\hline 1st & Kiryu (With soil) & Kiryu (With vegetation) & 5.0 & 0.01 \\
2 nd & $\begin{array}{l}\text { Rachi (bare) } \\
\text { (Without soil) }\end{array}$ & Kiryu (With vegetation) & 9.3 & 0.002 \\
3 rd & $\begin{array}{l}\text { Rachi (bare) } \\
\text { (Without soil) }\end{array}$ & $\begin{array}{l}\text { Rachi (bare) } \\
\text { (Without vegetation) }\end{array}$ & 9.3 & 0.04 \\
\hline
\end{tabular}

a runoff delay effect and are positive for both functions of flood control and water resources conversation.

Comparison of second and third calculation effects allows evaluation with forest vegetation. The annual minimum hour runoff volume in the third calculation without forest vegetation is about $0.04 \mathrm{~mm} \mathrm{~h}^{-1}$, whereas the volume in the second calculation with forest vegetation is $0.002 \mathrm{~mm} \mathrm{~h}^{-1}$, which is apparently low. Regarding the annual maximum hour runoff volume, discrimination is not possible by second and third calculations. They are regarded as equal to $9.3 \mathrm{~mm} \mathrm{~h}^{-1}$. Although the influence with and without of forest vegetation on the flooding control function is so small and is not noticed clearly, the negative influence on water resources conservation function is distinctively identified, demonstrating that the existence of forest vegetation is effective for reducing runoff volume during times of drought.

\subsection{Verification by observation data}

Results obtained using the Hy-Cy model were verified from observation data. However, only effects by forest vegetation can be verified.

\subsubsection{Paired catchment method}

Paired catchment method (Fig. 5) was used to verify the results by Hy-Cy model calculations. Using this method, more than two catchments are considered; also, two time periods are considered. These are control periods during which both forest soil and forest vegetation are well developed in the control and treatment catchments. The treatment periods are those in which forest soil and forest vegetation is well developed and underdeveloped in the control and treatment catchments, respectively. The influences of forest soil and forest vegetation are evaluated from relative changes of runoff volume from both catchments between both periods. Evaluating effects of forest vegetation can be done by removing the vegetation in the treatment catchment, in spite of remaining the vegetation in the control catchment. In contrast, it is not possible to produce artificially with the forest soil condition and without forest soil condition. Therefore, evaluation of forest soil effects from the observation data is not possible at present.

\subsubsection{The cases in Tatsunokuchi-yama experimental watershed}

Tatsunokuchi-yama experimental watershed $\left(34.70^{\circ} \mathrm{N}, 133.97^{\circ} \mathrm{E}\right)$ consists of Kitadani and Minamidani catchments. Since observations began in 1937, the Kitadani catchment has been covered with broad-leaved deciduous forest. In the Minamidani catchment, the forest was 


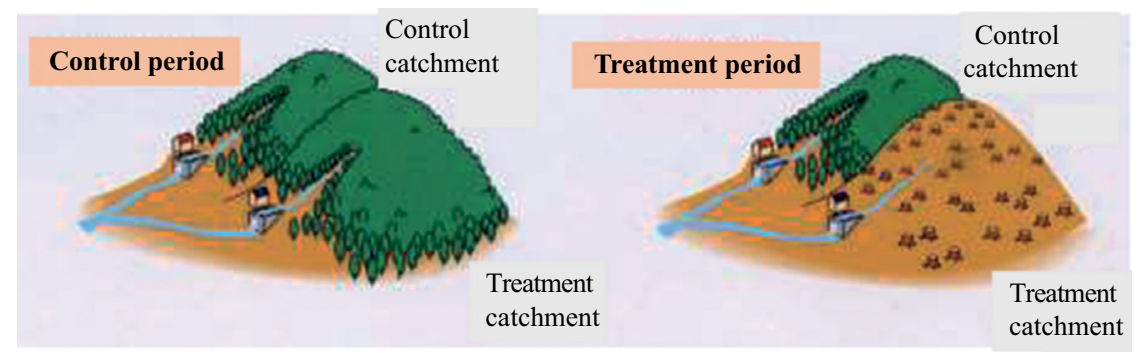

Figure 5: Outline of paired catchment experiment (Source: Tamai, 2020a).

damaged by a forest fire in 1960 and by pine wilt decease around 1981. Analyses were made using paired catchment method for which intervening years (1960-1966, 1981-1992) are regarded as treatment periods; others are control periods.

Runoff volumes of the 90th low level in 1 year (designated as low flow) of both catchments were compared (Fig. 6). $\square$ and $\bullet$ marks are from the treatment and control periods, respectively. Distribution of $\square$ is apparently above the $\bullet$ distribution. Low flow from the Minamidani catchment when forest exists is apparently less than when no forest exists. It is then noteworthy that trees in the Minamidani catchment are effective for runoff volume reduction at a low water level. This result agrees with the fact that forest vegetation is effective for reducing the annual minimum hourly runoff volume, as shown in Table 1.

The annual maximum daily runoff volume is portrayed in Fig. 7 in a similar manner to that used for Fig. 6. In Fig. 7, the distribution of $\square$ is overlapped on the distribution of $\bullet$. It can be seen that the impact on high water levels with and without forest vegetation is negligible.

\subsubsection{The cases in Sarukawa experimental watershed}

The results similar to Fig.7 at a high water level are obtained from cedar and cypress forest catchments in Sarukawa experimental watershed $\left(31.85^{\circ} \mathrm{N}, 131.22^{\circ} \mathrm{E}\right)$ consists with three catchments: No. 1, No. 2 and No. 3. In 1967, the cedar and cypress of No. 1 and No. 3 catchments were felled thoroughly, although the cedar and cypress of No. 2 catchment remain. The annual maximum daily runoff volume is shown in Fig. 8 in a manner similar to that in Fig. 7, for which the control periods are 1977 to 1981 and 1995 to 2005. Others are control periods. No clear difference is apparent between the distribution areas of $\square$ and $\bullet$, showing values in the treatment and control periods, respectively. No relative increase from No. 1 and 3 catchments in treatment period is recognized for the annual maximum daily runoff volume, compared with them in control periods.

\subsubsection{Verification results}

Influences of forest vegetation on the annual maximum daily runoff volume were evaluated for three cases (Figs. 7 and 8), but no clear influence was noted. This result agrees with the result demonstrating that the effect of forest vegetation on the annual maximum hourly runoff volume was not recognized clearly, as shown in Table 1.

As for the case of low flow, only one case in Tatsunokuchi-yama experimental watershed (Fig. 6) is shown, but similar results were obtained in Sarukawa experimental watershed by Tamai et al. [4]. These results agree with the results by second and third calculations by Hy-Cy model (Table 1). 


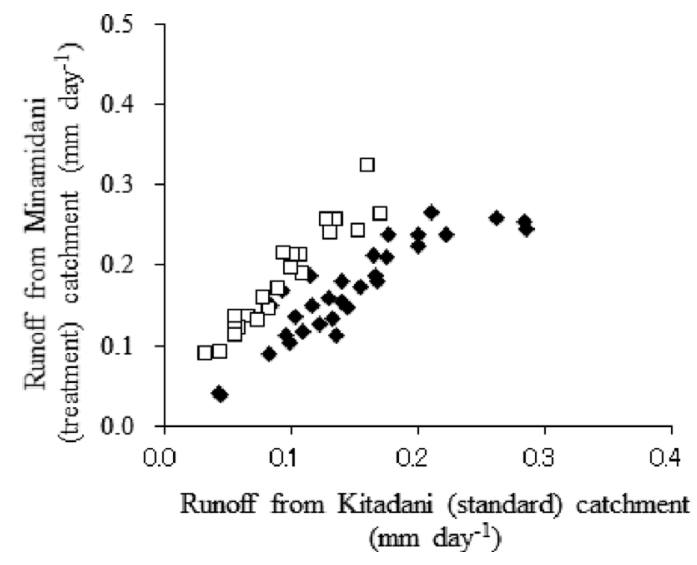

Figure 6: Comparison of 90th low level daily runoff in flow duration curves from Kitadani (Control) and Minami-dani (Treatment) catchments in Tatsunokuchi-yama Watershed (Source: Tamai et al., 2008).

$\bullet$ : Standard period; $\square$ : Treatment period.

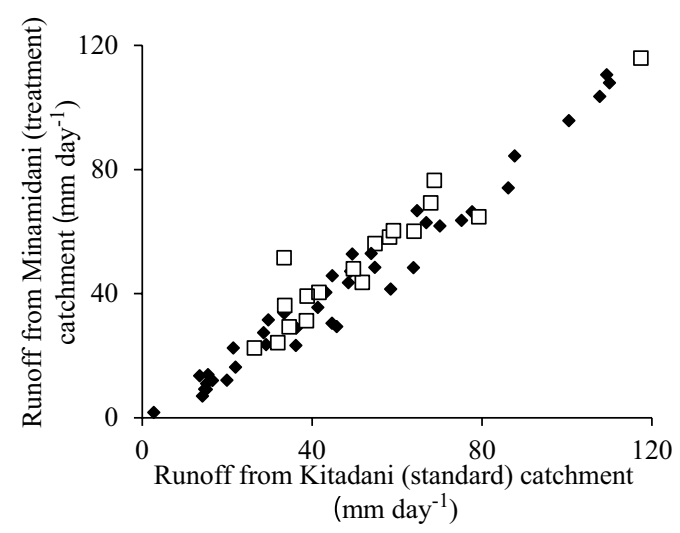

Figure 7: Comparison of first day (annual maximum) runoff in flow duration curves from Kitadani (standard) and Minamidani (treatment) catchments in Tatsunokuchi-yama Watershed (Source: Tamai, 2020b).

४: Standard period; $\square$ : Treatment period.

Consequently, the results of evaluation of effects of forest vegetation by Hy-Cy model upon runoff are shown to agree with the results obtained from analyses of observation data.

\subsection{Evaluation of forest maturity and forest functions}

Tani et al. [3] performed identification of Hy-Cy model parameters for not only Kiryu and Rachi (bare)catchments shownin Table 1, butalsoJakujocatchment $\left(34.93^{\circ} \mathrm{N}, 135.98^{\circ} \mathrm{E}\right)$ and F2 catchment $\left(34.92^{\circ} \mathrm{N}, 135.97^{\circ} \mathrm{E}\right)$ adjacent to Kiryu and Rachi (bare) catchments. Jakujo and F2 catchments are also based on weathered granite. Jakujo catchment used to be bare. Greenery work was applied to Jakujo catchment later than Kiryu catchment. Their tree and 

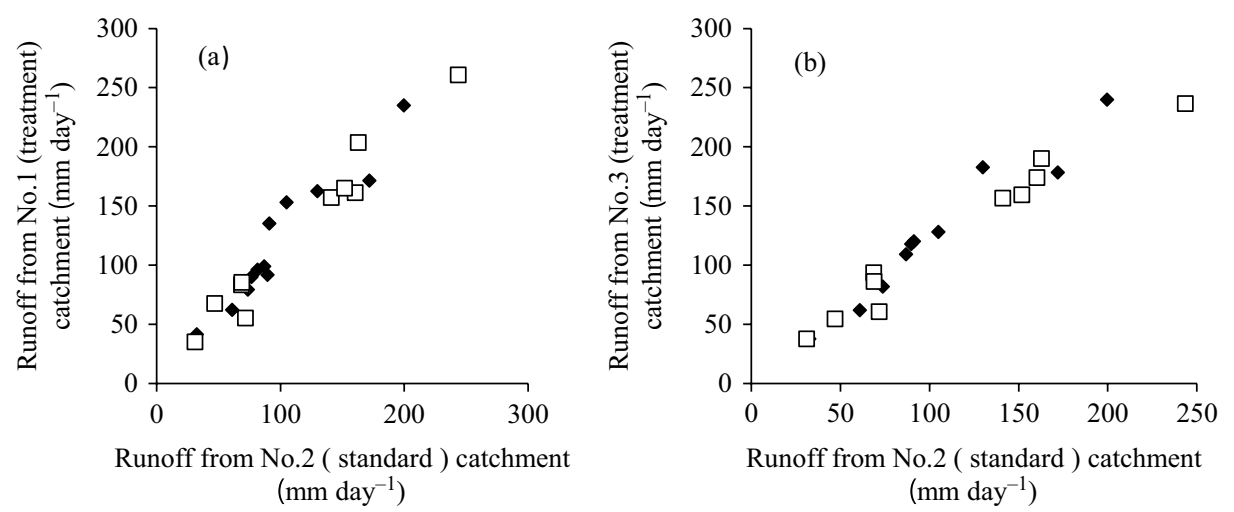

Figure 8: Comparison of 1st day (annual maximum) runoff in flow duration curves from standard (No. 2) and treated (No. 1 and No. 3 in (a) and (b), respectively) catchments in Sarukawa Watershed (Source: Tamai, 2020b).

$\bullet$ : Standard period; $\square$ : Treatment period.

soil are less developed than that of Kiryu catchment. F2 catchment belongs to the temple established in the 9th century. The forest soil in F2 catchment is well developed as classified into brown forest soil noted by Tani et al. [3]. The forest ages are 0 year for Rachi (bare) catchment, 46 years for Jakujo and 106 years for Kiryu, when runoff volume data were observed to identify the parameters by Tani et al. [3]. When F2 has been covered by forest since the 9th century, it might be said that the age of the forest is even older. Tani et al. [3] showed the flow duration curve as the figure obtained by entering the same precipitation data used for Table 1. Values read from the left and right ends of flow duration curves are presented in Fig. 9. The values for Rachi (bare) catchment present the condition of no forest soil or no forest vegetation. The annual maximum hourly runoff volume of Rachi (bare) catchment is about two times greater than those of the other three catchments. The annual minimum hourly runoff volume of Rachi (bare) catchment is also about three times greater than those of other three watersheds. Compared with Rachi (bare) catchment, the annual maximum and minimum hourly runoff volume from other three catchments with more than 46 years of forest are almost same.

\subsection{Conclusions of Evaluation and Verification}

Conclusions can be summarized as shown below.

The results of Hy-Cy model analysis show that developed forest soil reduces runoff volume at a high water level and increased runoff volume at a low water level by runoff delay effects.

Results of Hy-Cy model analysis show that the developed forest vegetation reduces the runoff volume at a low water level because of evapotranspiration. It has little influence on runoff volume at a high water level. This result is verified by analysis of data from actual observed runoff volume.

These conclusions mean that timber harvest does not directly increase flood risk. When forest soil is lost by erosion or land slide after timber harvest, flood risk is expected to become higher.

Results of Hy-Cy model analysis show that runoff delay effects are improved by forest soil development, but the intensity of the effect reaches its peak around 46 years old. Consequently, there are limits to improve the runoff delay effects. 

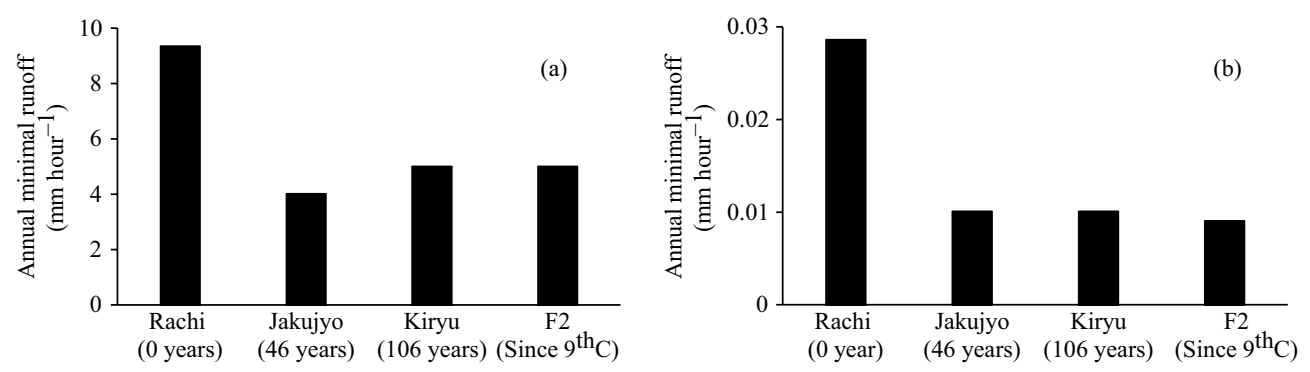

Figure 9: Comparison of annual maximum (a) and annual minimum (b) hourly runoff from watersheds with different ages since greenery work (Source: Tani et al., 2012).

\section{FOREST MANAGEMENT CONCEPT IN TERMS OF WATER RESOURCES CONSERVATION FUNCTIONS}

From the conclusions presented above, runoff delay effects by forest soil increase the runoff volume at drought. However, evapotranspiration effects by forest vegetation reduce it. When the annual minimum hourly runoff volumes are compared between the first and third calculations in Table 1, then the volume by third calculation without soil and without vegetation is greater. Additionally, as shown in Fig. 9, a minimum runoff volume of Rachi (bare) catchment alone is about three times greater than those of the other three watersheds, which indicates that forest vegetation effects are far greater than those of forest soil. If judgments are made using only this finding, then some people might misunderstand that the condition with forest soil and without forest vegetation is the preferred condition for water resources conservation.

However, forest vegetation has effects for preventing forest soil loss. Therefore, it is considered that when a condition with forest soil and without forest vegetation arises temporarily, forest soil has the risk to be lost and then supposed to migrate to a condition without forest soil and without forest vegetation. If this were the case, then both functions of flood control and water resources conservation would deteriorate. Because forest soil has the runoff delay effect. This effect is positive for both functions of flood control and water resources conservation. Forest vegetation should be maintained for water resources conservation function by preventing the forest soil loss.

As for measures used in areas where precipitation is lighter and water resources are extremely lacking, it can be selected as second best that the amount of forest vegetation is adjusted to the level at which forest soil can be maintained. This can be done to reduce transpiration and to increase runoff volume during times of drought. Forest soil is lost through surface erosion and land slide. The amount of forest vegetation should be found in light of such risks and comparisons incorporating increased runoff volumes in times of drought.

\section{REFERENCES}

[1] Fukushima, Y. \& Suzuki, M., Hydrologic model for mountain watersheds and its application to the continuous 10 years records at intervals of both a day and an hour of Kiryu Watershed, Shiga Prefecture (in Japanese). BULLETIN OF THE KYOTO UNIVERSITY FORESTS, 57, pp.162-185, 1986.

[2] Fukushima, Y., Influence of Forestation on Mountainside at Granite Highlands (in Japanese). WATER SCIENCE, 177, pp.17-34, 1987. 
[3] Tani, M., Fujimoto, M., Katsuyama, M., Kojima, N., Hosoda, I., Kosugi, K., Kosugi, Y. \& Nakamura, S., Predicting the dependencies of rainfall-runoff responses on human forest disturbances with soil loss based on the runoff mechanisms in granite and sedimentary rock mountains. HYDROLOGICAL PROCESSES, 26, pp.809-826, 2012.

[4] Tamai, K., Shimuzu, A., Hosoda, I., Miyabuchi, Y., Shimizu, T., Miyama, T., Kominami, Y. \& Asano, S., The Effect of various forest disturbances on water discharge duration curve -The Case Comparison between the Sarukawa experimental watershed in Miyazakishi and the Tatsunokuchi-yama experimental watershed in Okayama-shi (in Japanese). Bulletin of Forestry \& Forest Products Research Institute, 408, pp.111-120, 2008.

[5] Abe, T., Hattori, S., Tamai, K. \& Gotou, Y., Characteristics of water balance in a deciduous broad-leaved forest (in Japanese). Applied Forest Science, 6, pp.175-178, 1997.

[6] Tamai, K., Flood control function by forest (in Japanese). Sanrin, 1635, pp.66-73, 2020a.

[7] Tamai, K., Extinction effect of forest vegetation on the annual maximum daily runoff (in Japanese). Kyushu Journal of Forest Research, 73. pp.139-141, 2020 b. 